The necessity of regional lymph node dissection is debated. Most authors would advocate such dissection only if there are clnically palpable nodes. ${ }^{3}$ However, regional lymph nodes may become enlarged as a result of chronic infection and/or metastases. Therefore, the size of the nodes is not a dependable indicator of the presence of malignancy. With the present data, the variation in opinion continues. However, all patients should at least receive local excision with careful follow-up over at least three years. If lymph enlargement occurs, lymph node dissection is indicated. For primary tumours larger than $4 \mathrm{~cm}$, Glass ${ }^{7}$ advocates node dissection at the time of primary surgery. In a series of patients studied by Ames in 1980, $98 \%$ of all recurrence were seen within three years from the time of primary excision. This included $92 \%$ of all regional lymph node metastases and $88 \%$ of

1 Berkwits L, Yarkony GM, Lewis V. Marjolin's ulcer complicating a pressure ulcer: case report and literature review. Arch Phys Med Rehabil 1986; 67: 831-3.

2 Warren S. Minimal criteria to prove causation of traumatic or occupational neoplasms. Ann Surg 1943; 117: 585.

3 Novick M, Gard DA, Hardy SB, Spira M. Burn scar carcinoma: a review and analysis of 46 cases. $\mathcal{f}$ Trauma 1977; 17: 809-17.

4 Treves N, Pack GT. Development of cancer in burn scars: analysis and report of thirty-four cases. Surg Gynecol Obstet 1930; 51: 749-82.

5 Lawrence EA. Carcinoma arising in scars of thermal burns: with special reference to the influence of age at burn on length of induction period. Surg Gynecol Obstet 1952; 95: 579-88. the distant metastases. The patient who survives three years without metastases has an excellent prognosis.

Various histological types of neoplasia are found in Marjolin's ulcer, including melanoma, osteogenic sarcoma, liposarcoma, adenocarcinoma, fibrosarcoma, carcinosarcoma, carcinoma in situ, basal cell carcinoma, and squamous cell carcinoma. ${ }^{4}$ This variation is perhaps an indication of the malignant potential that is within each layer of the damaged skin (epidermis, dermis and subcutaneous layer). Of these histological types, the most commonly encountered is the squamous cell carcinoma, followed by the basal cell carcinoma. ${ }^{4,5}$ However, the histological finding of pseudoepitheliomatous hyperplasia causes difficulty in distinguishing between benign and malignant. At times, this may be impossible. ${ }^{10}$

6 Castillo JL, Goldsmith HS. Burn scar malignancy in a possibly depressed immunologic setting. Surg Forum 1968; 19: $511-3$.

7 Glass RL, Spratt JS Jr, Perez-Mesa C. Fate of inadequately excised epidermoid carcinoma of skin. Surg Gynecol Obstet 1966; 122: $245-8$

8 Reuler JB, Cooney TG. Pressure sore: pathophysiology and Reuler JB, Cooney TG. Pressure sore: pathophysiology and
principles of management. Ann Intern Med 1981; 94: 661 6.

9 Daskalopoulou D, Maounis N, Kokalis G, Liodandonaki P, Belezini E, Markidou S. The role of fine needle aspiration cytology in the diagnosis of primary skin tumors. Arch Anat Cytol Pathol 1993; 41: 75-81.

10 White $C$, Weidman FD. Pseudoepitheliomatous hyperplasia at margins of cutaneous ulcers. $¥ A M A 1927 ; 88$ : 1959-63.

\title{
Carcinoma of the sigmoid colon presenting as a scrotal swelling
}

\author{
NP Bryan, A Jackson, AT Raftery
}

\section{Department of Surgery, Northern General Hospital, Sheffield S5, UK NP Bryan A Jackson AT Raftery}

Correspondence to Dr NP Bryan, 45 Brighton Terrace Road, Crookes, Sheffield S10 1NT, UK

Accepted 21 March 1996

\begin{abstract}
Summary
A case of adenocarcinoma of the sigmoid colon, presenting as a testicular mass, is described. At sigmoid colectomy widespread metastases were found and only palliative care could be offered thereafter. The incidence and age of such a presentation and manner of spread of the occult primary are discussed.
\end{abstract}

Keywords: testicular metastasis, colonic carcinoma, occult primary

Metastatic tumours of the testis are unusual; even rarer are tumours presenting in the testis from occult primaries. We present a case and review the literature.

\section{Case report}

A fit 75-year-old man presented with a swelling in the right scrotum. On examination there was an epididymal cyst and a nodule was palpated separate from the inferior pole of the right testis. He was otherwise asymptomatic.

An ultrasound scan confirmed a solid mass ( $2 \mathrm{~cm}$ diameter), suspicious of malignancy, inferior to the right testicle. At orchidectomy a firm 2-cm nodule was found adjacent to the epididymal cyst (figure). It was external to the tunica vaginalis. There was a hydrocele of the cord and testis but no macroscopic patent processus vaginalis, although a microscopic connection with the peritoneal cavity could not be excluded. Histology confirmed the presence of a moderately differentiated adenocarcinoma. Tumour markers were positive for 


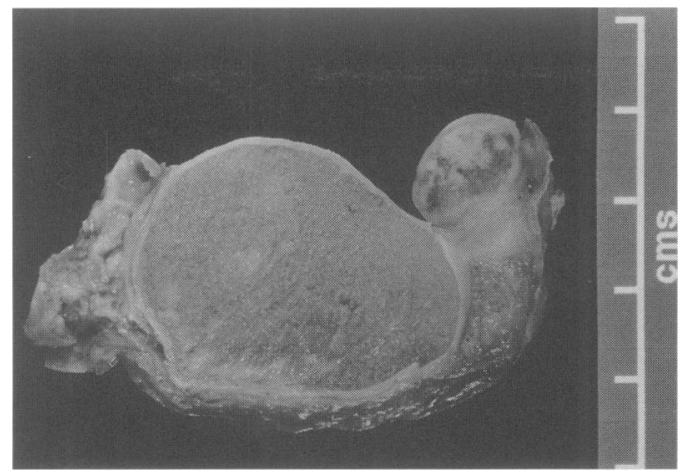

Table Tumours first presenting in the testis

\begin{tabular}{|c|c|}
\hline Site of occult primary & $\begin{array}{l}\text { Number presenting } \\
\text { in testis }\end{array}$ \\
\hline $\begin{array}{l}\text { Prostate }^{3,8} \\
\text { Colon }^{2,3,6-9} \\
\text { Kidney }^{3,9} \\
\text { Stomach }^{3,9,10} \\
\text { Pancreas }^{3,9} \\
\text { Carcinoid }^{3} \\
\text { Unknown }^{3} \\
\text { Total }\end{array}$ & $\begin{array}{l}3 \\
8 \\
3 \\
3 \\
2 \\
1 \\
1 \\
24\end{array}$ \\
\hline
\end{tabular}

Figure

carcinoembryonic antigen but negative for prostatic acid phosphatase and prostate-specific antigen, suggesting a primary tumour of the gastrointestinal tract.

Further investigation showed a tight, applecore structure of the rectosigmoid on barium enema and numerous hepatic metastases on abdominal ultrasound. Gastroscopy and a chest X-ray demonstrated no abnormality. At sigmoid colectomy a $3.5 \mathrm{~cm}$ constricting tumour of moderate to poorly differentiated adenocarcinoma (JASS group 4) was found, identical to the presenting lesion, with widespread peritoneal seedlings, lymphadenopathy and liver metastases. The patient recovered and was discharged after nine days, but had to be re-admitted three months later for symptoms of carcinomatosis from which he died shortly after.

\section{Discussion}

Some 200 cases of non-lymphomatous, scrotal metastases have been reported in the literature. In a series of scrotal tumours the incidence of metastatic tumours varied between $0.8 \%{ }^{1}$ and $3.6 \%$. In a review of reported cases the commonest primary was the prostate $(34.6 \%)$ followed by lung (17.3\%), malignant melanoma $(8.2 \%)$, colon $(7.7 \%)$, and kidney $(5.8 \%)$, as well as stomach, pancreas, carcinoid, neuroblastoma, retinoblastoma, penis, bladder, rectum, cylindroma, mesothelioma, thyroid, ureter, bile duct, liver, appendix and sarcoma. Only $6 \%$ of these cases presented with a scrotal

1 Pugh RCB. Testicular tumours - introduction. In: Pathology of the testis. Oxford: Blackwell Scientific Publications, 1976; of the testis 139.

2 Patel S

Patel SR, Richardson RL, Kvols L. Metastatic cancer to the testes: a report of 20 cases and review of the literature. $f$ Urol 1989; 142: $1003-5$.

3 Haupt HM, Mann RB, Trump DL, Abeloff MD. Metastatic carcinoma involving the testis. Clinical and pathological distinction from primary testicular neoplasms. Cancer 1984; 54: $709-14$

4 Eadie DGA. Presentation of carcinoma of the stomach as a left testicular tumour. Br f Surg 1962; 50: 156.

5 Hanash KE, Carney JA, Kelalis DP. Metastatic tumours to testicles: routes of metastasis. $\mathcal{F}$ Urol 1969; 102: 465.

\begin{tabular}{|l|}
\hline Learning points \\
- non-lymphomatous scrotal metastases are rare \\
the commonest occult primary tumour to \\
present in the testicle is from the large bowel \\
- orchidectomy is required for diagnosis, but \\
prognosis is poor and treatment only palliative \\
- presentation is mainly after the sixth decade \\
this tumour may have spread via lymphatics. \\
Other routes are venous, embolic and \\
transperitoneal
\end{tabular}

swelling and a truly occult primary tumour; relatively few of these $(15.4 \%)$ were of prostatic origin. ${ }^{2}$

Our review of the literature reveals that eight out of 24 colonic tumours presented in the testis (table). The mean age of presentation in one study was 59 years for non-lymphomatous, metastatic tumours in comparison with 31 years for germ cell tumours. ${ }^{3}$

A hydrocele of the cord and testis was found in this case. It is possible, therefore, that while no macroscopic patent processus vaginalis was seen, there were microscopic channels allowing communication between the peritoneum and the tunica vaginalis resulting in spread of tumour by that route. The widespread lymphatic involvement at laparotomy also suggests that retrograde spread via lymphatics could be another route of spread for gastrointestinal malignancies to the scrotum. ${ }^{4,5}$ Other tumours may well spread by venous, embolic or transductal routes.

6 Rasmussen HH, Schroder P. Testicular hydrocele: an initial sign of colon carcinoma. Acta Chir Scand 1988; 154: 65-6. 7 Taviaux R, Bove L. Cancer of the transverse colon disclosed by right testicular mass. Review of the literature a propos of a case. f Chir (Paris) 1992; 129: 51-2.

8 Meacham RB, Mata JA, Espada R, Wheeler TM, Schum CW, Scardino PT. Testicular metastasis as the first manifestation of colon carcinoma. $\mathcal{F}$ Urol 1988; 140: 621 - 2 .

9 Ramesh K. Epididymal metastasis as the first presentin feature of an asymptomatic caecal cancer. Cent Afr $\mathcal{f}$ Med 1993; 39: 146-7.

10 Muir GH, Fischer C. Gastric carcinoma presenting with testicular metastasis. Br f Urol 1994; 73: 713-4. 